\title{
Triboluminescent Electrospun Mats with Blue-Green Emission under Mechanical Force
}

\author{
Anıl İncel, ${ }^{\dagger, \|}$ Canan Varlikli, ${ }^{\ddagger}$ Colin D. McMillen, ${ }^{\S}$ and Mustafa M. Demir*,† \\ ${ }^{\dagger}$ Department of Materials Science and Engineering and ${ }^{\ddagger}$ Department of Photonics, İzmir Institute of Technology, Urla 35430, İzmir, \\ Turkey \\ ${ }^{\S}$ Department of Chemistry, Clemson University, 219 Hunter Laboratories, Clemson, South Carolina 29634, United States
}

Supporting Information

\begin{abstract}
Fibrous mechanosensing elements can provide information about the direction of crack propagation and the mechanism of material failure when they are homogeneously dispersed into the bulk volume of materials. A fabrication strategy of fibrous systems showing triboluminescent (TL) responses is in high demand for such applications. In this work, micrometer-sized $\mathrm{Cu}(\mathrm{NCS})(\mathrm{py})_{2}\left(\mathrm{PPh}_{3}\right)$ crystals were synthesized, and polymeric fibrous mats containing the TL crystals were obtained via electrospinning as a stress probe for the determination of mechanical impact. Four different polymeric systems have been employed (PMMA, PS, PU, and PVDF), and the mechano-optical sensing performance of electrospun mats of the polymer-crystal composites was measured. Photophysical properties (quantum yield, band gap, and broadness of the emission) of the TL crystal/electrospun mat composites were also studied. TL and PL emission maxima of the PU-based composite mat show identical behavior due to the chemical affinity between the two structures and the smallest fiber diameter. Moreover, the PU fiber mats exhibit long-lived bluish-green emission persisting over a large number of drops.
\end{abstract}

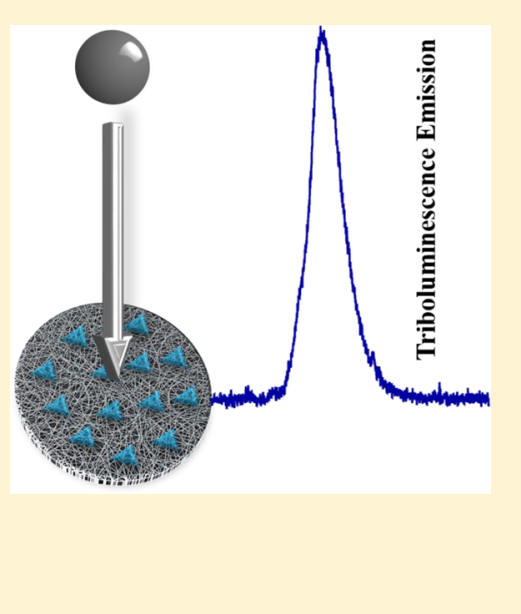

\section{INTRODUCTION}

Stability and stress-sensing elements are highly desirable in a variety of applications in materials engineering. ${ }^{1-3}$ In particular, monitoring the direction of failure in materials can provide information about the mechanism of failure. The key challenge is to develop and control reproducible signals from the sensing elements upon mechanical action. Recent advances in materials science have produced advances in such mechano-optical sensor materials. One mechanism studied is triboluminescence (TL), where light emission is produced from materials under mechanical impact. ${ }^{1-5}$ The integration of TL crystalline particles into a substrate offers significant potential in the development of impact-sensing technology. ${ }^{1-15}$ In recent years, various $\mathrm{TL}$ materials such as $\mathrm{ZnS} / \mathrm{Mn},{ }^{1} \mathrm{Y}_{2} \mathrm{O}_{3}$ and $\mathrm{Y}_{2} \mathrm{O}_{3} / \mathrm{Eu}^{2}{ }^{2}$ $\mathrm{EuD}_{4}$ TEA, ${ }^{3,4} \mathrm{MgD}_{4} \mathrm{TEA},{ }^{5} \mathrm{ZnO}$ microsized particles, ${ }^{6} \mathrm{CaAl}_{2} \mathrm{O}_{4}$ and $\mathrm{MgAl}_{2} \mathrm{O}_{4},{ }^{7} \mathrm{SrAl}_{2} \mathrm{O}_{4},{ }^{8} \mathrm{Ln} / \mathrm{SrAl}_{2} \mathrm{O}_{4},{ }^{9} \mathrm{BaAl}_{2} \mathrm{SiO}_{8},{ }^{10} 3,6-$ dibromocarbazole, ${ }^{11} \mathrm{~N}$-isopropylcarbazole, ${ }^{12}$ ester derivatives of 9-anthracenecarboxylic acid, ${ }^{13}$ and $N$-phenyl imide compounds ${ }^{14}$ were introduced in the literature. Among these TL materials, organometallic compounds are particularly attractive, allowing the development of noncentrosymmetric structures with accompanying intense triboluminescence, a long-lived quantum yield, and good chemical stability.

The $\mathrm{Cu}(\mathrm{I})$-based TL material, $\mathrm{Cu}(\mathrm{NCS})(\mathrm{py})_{2}\left(\mathrm{PPh}_{3}\right)$, is a useful blue-green-emitting luminescent material. The organometallic complex consists of copper(I) thiocyanate and two ligands, pyridine and triphenylphosphine, behaving as both electron-donating and ancillary linkages to neutralize and stabilize the coordination. The synthesis procedure for this compound is well known, and the system is suitable for obtaining triangular crystalline particles. ${ }^{15}$

During a typical TL process, the materials are fractured; therefore, for a possible sensor application, the amount of TL material in the medium gains importance. In the current literature, new TL materials are typically reported with only their solid-state TL responses. However, for practical applications the advantages of polymer composites are incontrovertible, and it is known that the PL properties of the molecule/crystal in a polymer composite can differ depending on the chemical nature of the bare polymer matrix. Although PL and TL follow two different mechanisms, the host polymer matrix would alter the amount of molecule/crystal and consequently influence the TL properties.

Furthermore, because TL performance is associated with the crystalline form of a material, the dissolution of the crystals destroys the TL signal. ${ }^{16}$ A rough substrate that can hold the maximum number of TL crystals is needed to optimize the practical applications. A number of approaches have been explored, and polymer-based composites containing crystalline particles have consequently attracted a great deal of interest in the field of light-emitting materials. ${ }^{1,16-29}$ Polymeric films composed of particles are recognized to have excellent physical,

Received: March 27, 2017

Revised: $\quad$ May 8, 2017

Published: May 8, 2017 
mechanical, optical, and electrical properties that are necessary for applications in sensor systems. ${ }^{30-35}$

Electrospun fiber mats are a flexible and easily prepared substrate for functional nanomaterials such as catalytic nanoparticles, ${ }^{36-38}$ surface functional species, ${ }^{39}$ optical elements, ${ }^{40}$ and so forth. In this approach, a high potential difference is applied to a viscous polymer solution. When the applied electrical force overcomes the surface tension of the solution, a charged jet is developed, and the evaporation of solvent leaves behind a nonwoven mat of continuous fibers having submicrometer thickness. ${ }^{41}$

In this study, $\mathrm{Cu}(\mathrm{NCS})(\mathrm{py})_{2}\left(\mathrm{PPh}_{3}\right)$ crystals were used to impregnate the surface of nonwoven electrospun mats prepared from different polymers, including poly(methyl methacrylate), PMMA; polystyrene, PS; polyurethane, PU; and poly(vinylidene fluoride), PVDF. The polymers employed vary in terms of their morphology and mechanical and electrical properties. For instance, the first two polymers are amorphous, and the last two polymers have a semicrystalline nature. PU is an elastic polymer. PVDF has piezoelectric properties. The TL emission performance of the resulting fibrous composite system was measured with a homemade drop tower system. The triboluminescent performance of the composites was studied under mechanical impact over the range of $0.98-4.98 \mathrm{~N}$.

\section{EXPERIMENTAL DESIGN}

Materials and Methods. Copper(I) thiocyanate (99\%), triphenylphosphine (99\%), pyridine (anhydrous, 99.8\%), poly(methyl methacrylate) (PMMA) $(350 \mathrm{kDa})$, polystyrene (PS) $(350 \mathrm{kDa})$, polyurethane (PU), and poly(vinylidene fluoride) (PVDF) (280 kDa) ethanol ( $\geq 99.8 \%)$ were purchased from Sigma-Aldrich (St. Louis, MO, USA). All other reagents and solvents are available in analytical grade and were used as received. Scanning electron microscopy (SEM) performed with an FEI Quanta 250 FEG (Hillsboro, OR, USA) was used to characterize surface morphologies. The parameters for imagining were $2.0 \mathrm{kV}, 2.0 \mathrm{~nm}$, secondary electrons, and 6.5 $\mathrm{mm}$ for the accelerating voltage, spot size, detector type, and working distance, respectively. Fluorescent images under a blue filter (435-480 $\mathrm{nm}$ ) were recorded using an Olympus IX2ILL100 fluorescence microscope (Lambertville, NJ, USA). Photoluminescence emission spectra were recorded using a Varian Cary fluorescence spectrophotometer (Palo Alto, CA, USA). A homemade drop tower system was designed and prepared and consisted of a USB2000+ preconfigured 200-850 nm UV-vis spectrophotometer and fiber optic cable (Ocean Optics, Winter Park, FL, USA). Single crystal X-ray diffraction data was collected at $100(2) \mathrm{K}$ on a Bruker D8 Venture diffractometer using Mo K $\alpha$ radiation $(\lambda=0.71073 \AA)$ and a Photon 100 detector. Photophysical properties were characterized using an FS5 spectrofluorometer (Edinburgh, U.K.).

Synthesis of $\mathrm{Cu}(\mathrm{NCS})(\mathrm{py})_{2}\left(\mathrm{PPh}_{3}\right)$. The synthesis of the target $\mathrm{Cu}(\mathrm{I})$ complex was performed according to the literature. ${ }^{15}$ As a short summary, $1.00 \mathrm{mmol}$ of CuNCS and $1.00 \mathrm{mmol}$ of $\mathrm{PPh}_{3}$ were dissolved in $5 \mathrm{~mL}$ of pyridine and stirred at $70{ }^{\circ} \mathrm{C}$ for $3 \mathrm{~h}$ (Scheme 1 ). When the reaction was complete, a dark-blue solution was obtained. The solution was allowed to slowly cool overnight. At the end of the cooling process, pale-yellow crystals were obtained by vacuum filtration and rinsed with toluene.

Crystallography of $\mathrm{Cu}(\mathrm{NCS})(\mathrm{py})_{2}\left(\mathrm{PPh}_{3}\right)$. A pale-yellow blocklike crystal having approximate dimensions of $0.081 \times$ $0.168 \times 0.256 \mathrm{~mm}^{3}$ was used for the data collection. Diffraction
Scheme 1. Synthesis of the $\mathrm{Cu}(\mathrm{NCS})(\mathrm{py})_{2}\left(\mathrm{PPh}_{3}\right)$ Complex

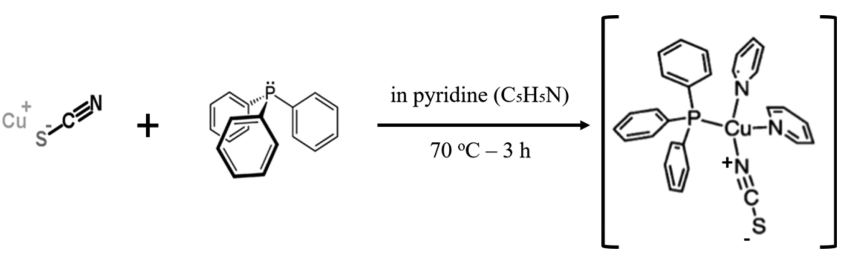

data were measured using Mo $\mathrm{K} \alpha$ radiation $(\lambda=0.71073 \AA)$ and a Photon 100 detector. A total of 29970 reflections were measured, of which 5319 were independent $\left(R_{\text {int }}=0.0298\right)$. $\mathrm{Cu}(\mathrm{NCS})(\mathrm{py})_{2}\left(\mathrm{PPh}_{3}\right)$ was found to crystallize in the monoclinic crystal system with $a=9.4006(4) \AA, b=$ $15.1492(7) \AA, c=10.2153(4) \AA$, and $\beta=116.9660(10)^{\circ}$. The systematic absences in the data were indicative of space group $P 2_{1}$. The structure was solved by intrinsic phasing (SHELXT) and subsequently refined by full matrix leastsquares techniques (SHELXL) on $F^{2}{ }^{42}$ All non-hydrogen atoms were refined anisotropically. Hydrogen atoms were placed geometrically, using appropriate riding models. Final $R$ values of $R 1=0.0185$ and $w R 2=0.0509$ were obtained on the basis of the observed data.

Preparation of the Composites. In the preparation of the composite materials, electrospun mats were used as the substrates and crystalline particles were used to impregnate their surfaces. $\mathrm{Cu}(\mathrm{NCS})(\mathrm{py})_{2}\left(\mathrm{PPh}_{3}\right)$ crystalline particles were used to impregnate four different polymeric mats, which are PMMA, PS, PU, and PVDF. Each polymer was first dissolved in $\mathrm{N}, \mathrm{N}$-dimethylformamide (DMF). Then, each film was prepared by electrospinning the dissolved polymer solution. Electrospinning conditions were fixed as $18 \mathrm{kV}, 25 \mathrm{~cm}, 4 \mathrm{~mL} / \mathrm{h}$, and $50 \%$ for the applied voltage, spinning distance, pumping rate, and humidity of air, respectively. Crystalline particles of $\mathrm{Cu}(\mathrm{NCS})(\mathrm{py})_{2}\left(\mathrm{PPh}_{3}\right)$ were dispersed in distilled water. The electrospun films were cut to approximately $1 \mathrm{~cm}$ in size, and each film was treated with the crystalline dispersion to fabricate the composite film. Finally, the same set of samples with similar $\mathrm{Cu}(\mathrm{NCS})(\mathrm{py})_{2}\left(\mathrm{PPh}_{3}\right)$ content was prepared by an alternative method called blending. In this approach, TL crystals were first dissolved in the polymer solution, and then the homogeneous solution was subjected to electrospinning.

Measurement of Triboluminescence. The triboluminescence (TL) performance of the $\mathrm{Cu}(\mathrm{NCS})(\mathrm{py})_{2}\left(\mathrm{PPh}_{3}\right)$ crystalline particles and electrospun mat-based composites was measured by using a drop tower mechanism specifically designed for TL testing. The material was placed in a sample holder within a black box. A $50 \mathrm{~g}$ steel ball with a diameter of 1 $\mathrm{cm}$ was positioned on a pull able pin at a set distance of $40 \mathrm{in}$. $(100 \mathrm{~cm})$ above the material. When the pin is pulled, the ball falls and hits the material, and TL emission occurs. A fiber optic cable preinserted directly through a small hole inside the black box can capture and transfer the resulting impact radiation to the spectrophotometer. TL intensity versus wavelength curves are obtained in quick view fluorescence mode. For the impact from a falling object, potential energy is assumed to convert to kinetic energy without dissipation so that a drop from $50.0 \mathrm{~cm}$ height causes $2.45 \mathrm{~N}$ of mechanical impact for the measurement of the composite's TL response.

\section{RESULTS AND DISCUSSION}

Characterization and Structure of $\mathrm{Cu}(\mathrm{NCS})(\mathrm{py})_{2}\left(\mathrm{PPh}_{3}\right)$. The morphology of the as-synthesized $\mathrm{Cu}(\mathrm{NCS})(\mathrm{py})_{2}\left(\mathrm{PPh}_{3}\right)$ 

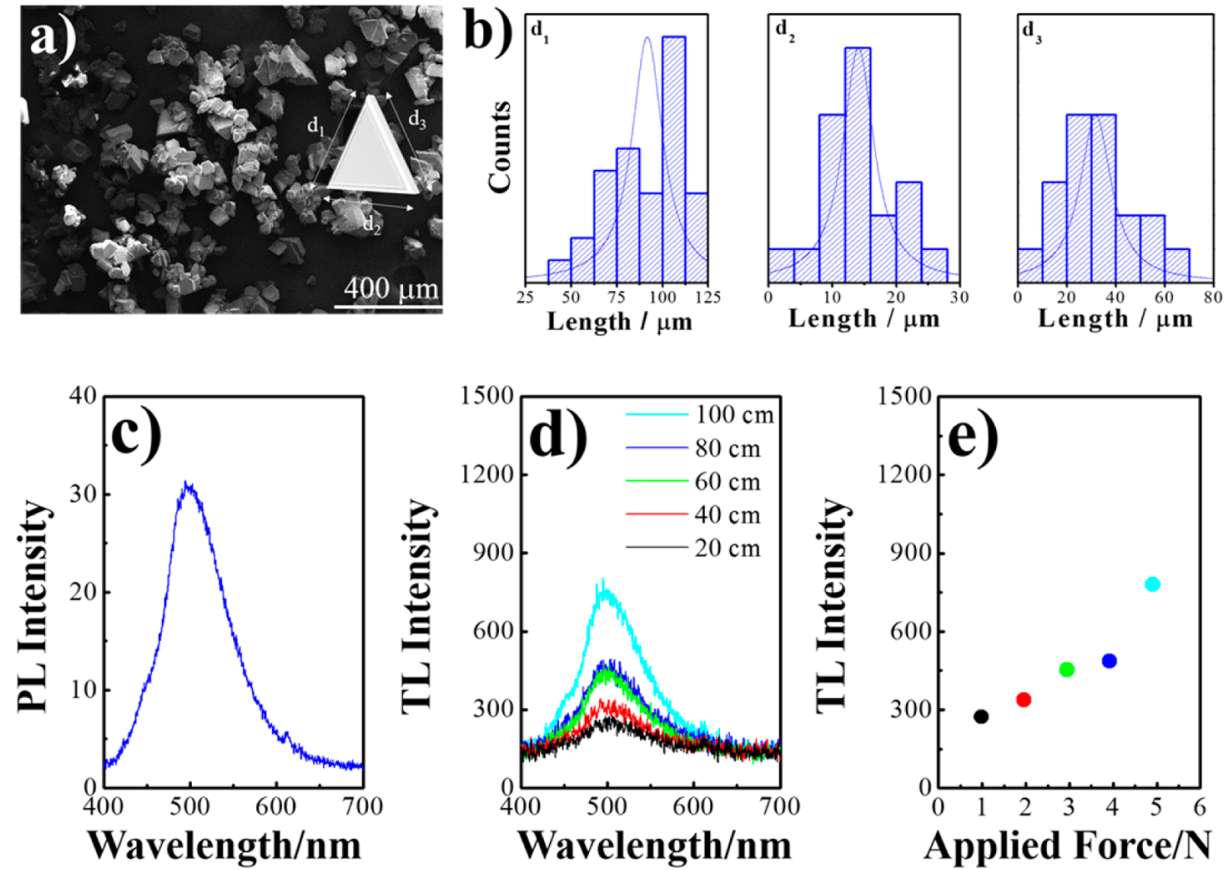

Figure 1. Characterization of the $\mathrm{Cu}(\mathrm{I})$ complex: SEM image (a); particle size distribution (b); PL spectrum of the $87 \mu \mathrm{M}$ complex in DMF (c); TL spectrum of $25 \mathrm{mg}$ crystalline particles (d); and TL spectrum with respect to applied force from 0.98 to $4.98 \mathrm{~N}$ (e).

crystalline particles was determined by using SEM. Figure 1a shows a representative electron micrograph of the crystalline powder. There are a number of larger individual crystals in powder assembled into a triangular shape, and the overall particle size distribution is presented in Figure 1b. Each length of individual crystal was measured with the ImageJ program. Three lengths show a Gaussian distribution with average sizes of $100 \pm 25,15 \pm 10$, and $40 \pm 20 \mu \mathrm{m}$. The photoluminescence of $\mathrm{Cu}(\mathrm{NCS})(\mathrm{py})_{2}\left(\mathrm{PPh}_{3}\right)(87 \mu \mathrm{M})$ was measured in DMF, and the spectrum is given in Figure 1c. The complex gives bluish-green luminescence with a peak maximum of 496 $\mathrm{nm}$ that is classically observed for the transitions of $\mathrm{d}$ orbitals of $\mathrm{Cu}$ and $\pi-\pi^{*}$ transitions of aromatic ligands. The TL spectrum of the as-prepared $\mathrm{Cu}(\mathrm{NCS})(\mathrm{py})_{2}\left(\mathrm{PPh}_{3}\right)(25 \mathrm{mg})$ particles was obtained using the drop tower system, and the TL spectra as a function of height are given in Figure 1d. The TL signals occur at $496 \mathrm{~nm}$, having the same maximum as the PL spectrum. The taller height is translated to a larger applied compression force on the crystalline particles; therefore, greater emission was observed from the $100 \mathrm{~cm}$ height. This TL emission is also characterized with respect to applied force and is shown in Figure 1e. Regardless of the impact velocity (developed from the drops from different heights), the wavelength and the shape of the spectra remain unchanged. Not surprisingly, increasing the impact velocity increases the intensity of the signal. While the applied force was changing from 0.98 to $4.98 \mathrm{~N}$, the intensity of the TL emission increased more than 2-fold.

The molecular structure consists of the four-coordinate $\mathrm{Cu}(\mathrm{I})$ center (Figure 2a) in distorted tetrahedral geometry $\left(\mathrm{N}-\mathrm{Cu}-\mathrm{N}=99.59\right.$ to $106.88^{\circ} ; \mathrm{N}-\mathrm{Cu}-\mathrm{P}=115.38^{\circ}$ to $\left.116.23^{\circ}\right)$ for the $\mathrm{N}$-bonded thiocyanate, triphenylphosphine, and two pyridine ligands. An important feature enabling TL is the lack of a center of symmetry characteristic of space group $P 2_{1}$, and the proper absolute structure was confirmed by a Flack parameter of $0.010(11)$. The molecules pack in a manner by which the $\mathrm{Cu}(\mathrm{I})$ centers maintain a polar directionality along the $b$ axis throughout the structure (Figure 2b). When any mechanical force is applied, the TL emission might originate from the breaking of copper-nitrogen bonds. The physical deformation of the molecular structure causes charge separation between positively ( $\mathrm{Cu}$ cations) and negatively ( $\mathrm{N}$ anions) charged species. This charge separation may produce an electrical field, leading to TL emission.

Triboluminescence of the Composite. Crystalline $\mathrm{Cu}$ $(\mathrm{NCS})(\mathrm{py})_{2}\left(\mathrm{PPh}_{3}\right)$ particles were incorporated onto the surfaces of electrospun mats of four polymers. The TL performance of the composite was measured by the drop tower system (Figure 3a) in a fashion similar to the measurement on the as-prepared crystalline powder above. Figure $3 b, c$ presents the TL spectra of $\mathrm{Cu}(\mathrm{NCS})(\mathrm{py})_{2}\left(\mathrm{PPh}_{3}\right)$ associated on electrospun mats of PMMA, PS, PU, and PVDF as a function of the number of drops. The TL emission shows a different response with respect to the chemistry of the polymer in terms of the TL intensity from the first impact. The first TL intensities of the composites are 1200, 2500, 4000, and 2750 counts/s for PMMA, PS, PU, and PVDF, respectively. Moreover, the TL response of composite mats (Figure $3 \mathrm{~b}$ ) is quenched after 3, 5, and 6 drops for PMMA, PS, and PVDF, respectively. The TL response of the same crystals can withstand 8 drops for the PU-based composite. We note that the wavelength and profile of the TL emission remain unchanged over consecutive drops, and there is a gradual loss in intensity as the composite becomes quenched (Figure 3c). For comparison, a composite prepared by the blending method exhibited no TL response upon application of mechanical force (Figure $\mathrm{S} 1)$. In the dissolution process, $\mathrm{Cu}(\mathrm{NCS})(\mathrm{py})_{2}\left(\mathrm{PPh}_{3}\right)$ crystalline particles were molecularly dispersed and the longrange crystalline structure was lost, leading to the loss of the TL properties.

It has been demonstrated that the TL emission depends on the size of the crystalline particles. ${ }^{43,44}$ When the number of drops increases, i.e., the crystals are beaten many times, the size 
a)

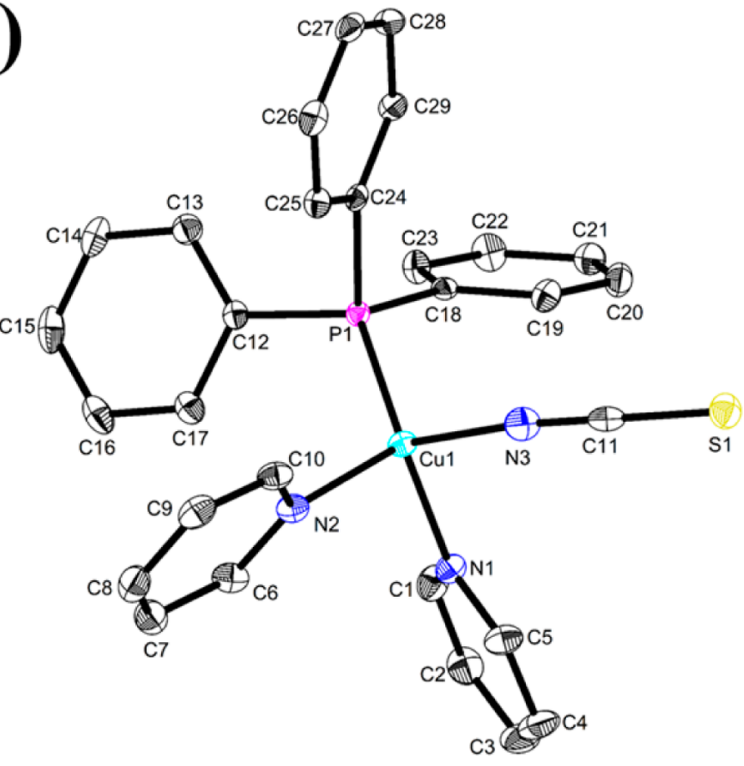

b)

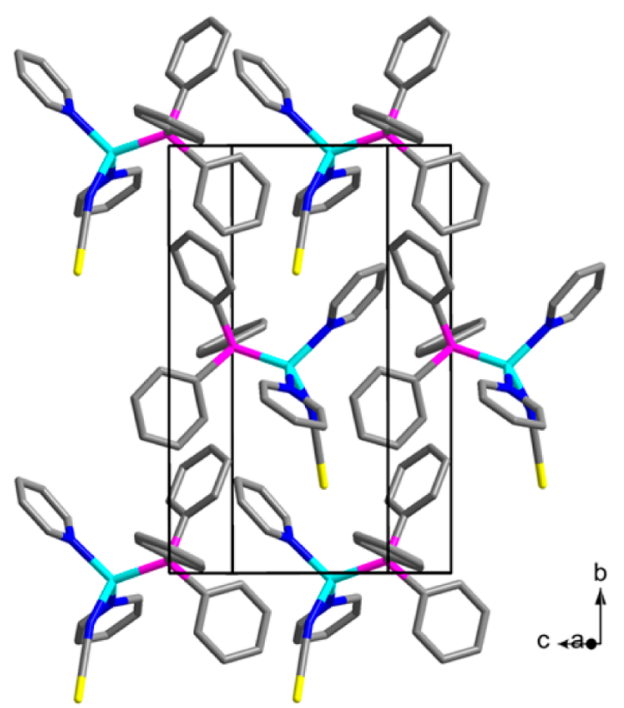

Figure 2. Molecular structure (a) and polar directionality (b) of $\mathrm{Cu}(\mathrm{NCS})(\mathrm{py})_{2}\left(\mathrm{PPh}_{3}\right)$.

of the crystalline particles becomes smaller. SEM images of crystalline particles were periodically captured after each drop. Figure 4 shows the images of initial crystals and after the first, third, fifth, and eighth drops. All distributions show Gaussian behavior with mean diameters as follows: $120 \pm 20,100 \pm 15$, $80 \pm 12,50 \pm 10$, and $30 \pm 8 \mu \mathrm{m}$, respectively. It is inevitable that the particle size of crystals decreases with the increasing number of drops, and this is likely a source of decreasing TL intensity with consecutive drops.

The physical properties of the solid substrate also play an important role in influencing the TL performance of the composites. The electrospun mat prepared using PU exhibits representative fiber morphology. Figure 5a shows an SEM image of a PU-based composite prepared by surface impregnation. A uniform distribution of crystalline particles is observed on the surface of the PU electrospun mat. In the case
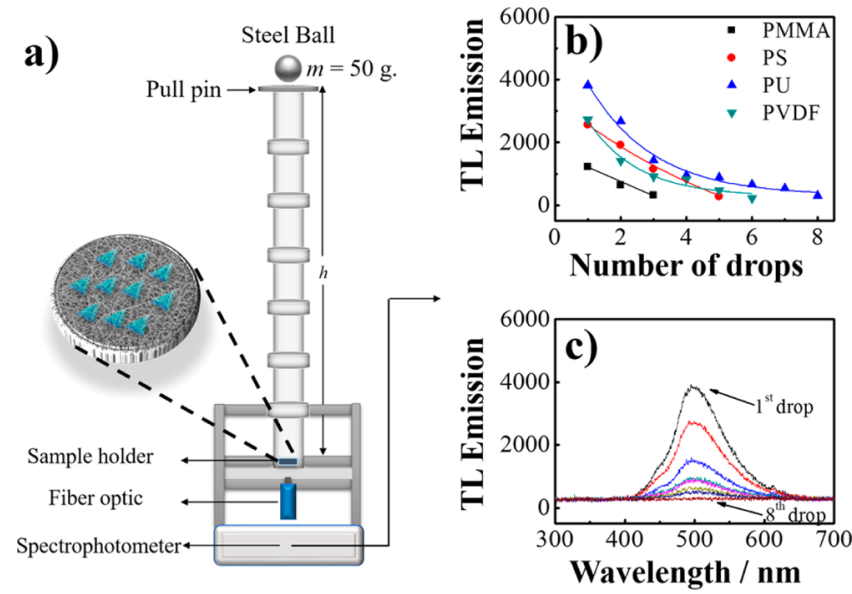

Figure 3. Drop tower system (a). TL emission of the composites prepared by PMMA, PS, PVDF, and PU as a function of the number of drops (b). TL response of the PU composite (c).
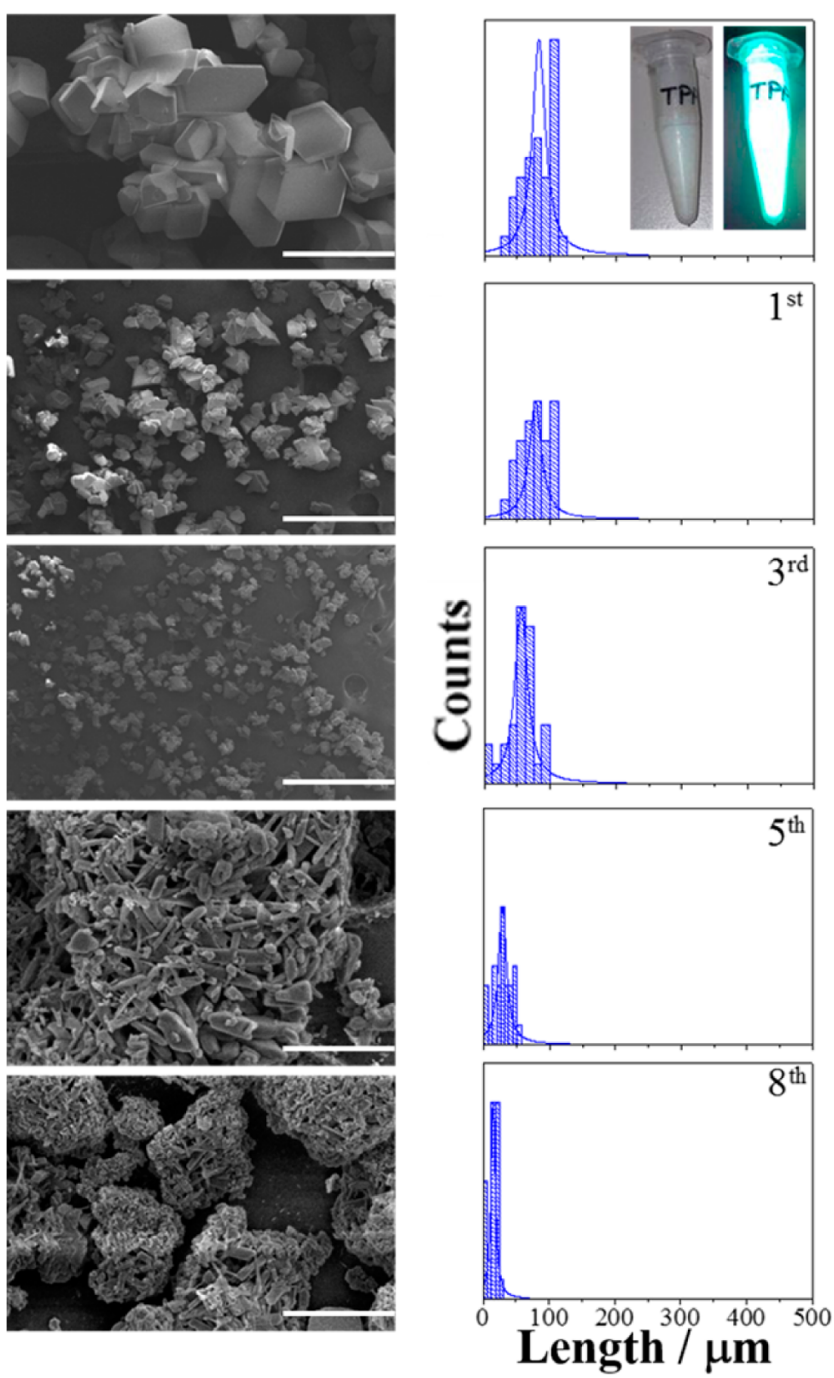

Figure 4. SEM images (scale bar $=400 \mu \mathrm{m}$ ) and corresponding particle size distribution of the $\mathrm{Cu}(\mathrm{I})$ complex before and after mechanical action. (Inset) Photographic images of crystals before and after UV light exposure.

of the PU electrospun mat prepared by blending (Figure $5 b$ ), there are no crystals embedded in the surface (rather, the $\mathrm{Cu}(\mathrm{I})$ 

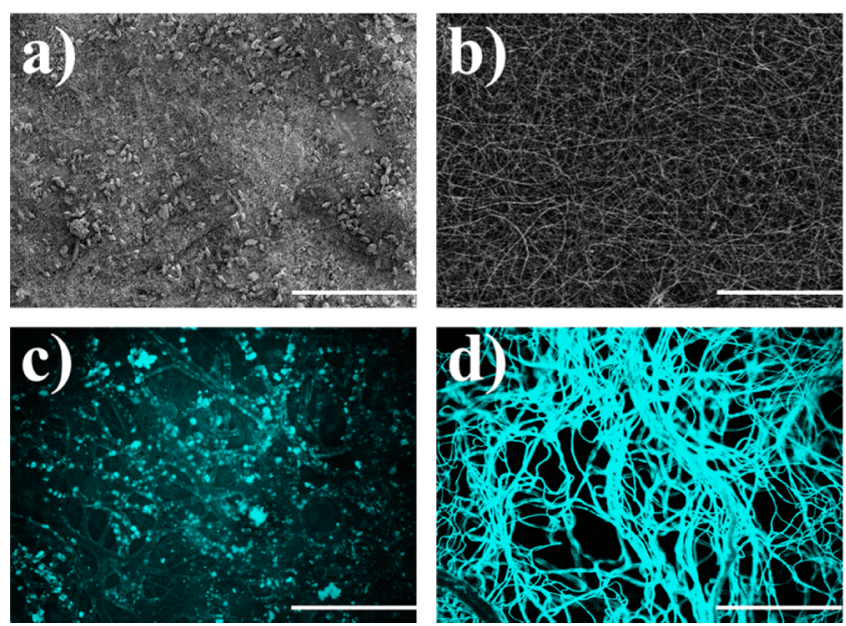

Figure 5. SEM (a, b) and FM (c, d) images (scale bar $=200 \mu \mathrm{m})$ of the composite mats prepared by both surface impregnation and blending.

complex is molecularly dissolved in the fiber volume), explaining why no TL response was observed, at least for the concentration of the $\mathrm{Cu}(\mathrm{I})$ complex employed in this work.

The electrospun mats show typical fiber morphology with varying fiber diameter even though each fiber mat was fabricated under the same conditions. The fiber diameter of PMMA, PS, PU, and PVDF electrospun films is 300, 100, 30, and $80 \mathrm{~nm}$, respectively (Figure S2). The fiber diameter in the electrospun mat governs the number of TL crystals that may be held on the surface. The number of $\mathrm{Cu}(\mathrm{NCS})(\mathrm{py})_{2}\left(\mathrm{PPh}_{3}\right)$ crystalline particles loaded onto the electrospun film was estimated by taking the difference between the total number of crystals in the dispersion solution, and the remaining number of crystals in the dispersion solution after treatment. Each measurement was performed three times. The average weight percentage of crystalline particles loaded into each composite was measured to be $66 \pm 2,70 \pm 2,85 \pm 5$, and $74 \pm 4 \%$ for the composites of PMMA, PS, PU, and PVDF, respectively. The PU substrate exhibited the highest retention of crystalline particles, and that composite consequently also had the largest number of fibers. These fibers were also thinner fibers, which have the potential to hold a greater number of crystals because of sieving effects of the smaller interfiber spacing. There may also be chemical affinity between $\mathrm{PU}$ chains and the $\mathrm{Cu}(\mathrm{I})$ complex.

The color signal of the TL crystals embedded on the composite was examined using fluorescence microscopy (FM) upon excitation with UV light $(\lambda=365 \mathrm{~nm})$. The composite prepared by $\mathrm{PU}$ is shown as a representative example (Figure $5 c)$. It is well known that the polymer substrates do not exhibit an intrinsic luminescence, and thus the observed optical signal originates from the $\mathrm{Cu}(\mathrm{I})$ complex. The emission indicates that the crystalline particles were uniformly distributed on the surface of the PU electrospun film, and the signal originates from the crystalline particles embedded on the fibers (Figure 5c). Alternatively, when the analogous PU composite prepared by blending (Figure $5 \mathrm{~d}$ ) is studied, the blue emission occurs homogeneously from the whole surface of the electrospun mat as a result of the integration of the $\mathrm{Cu}(\mathrm{I})$ complex into the fibers themselves on a molecular level. Again, no meaningful TL signal is achieved from the composites prepared by blending due to the loss of the crystalline character of the chromophore.
Photophysical Properties of $\mathrm{Cu}(\mathrm{NCS})(\mathrm{py})_{2}\left(\mathrm{PPh}_{3}\right)$ and Composites. Room-temperature excitation, photoluminescence (PL), and triboluminescence (TL) spectra of the $\mathrm{Cu}(\mathrm{NCS})(\mathrm{py})_{2}\left(\mathrm{PPh}_{3}\right)$ complex in the solid state and its composite with various polymeric fiber mats are shown in Figures 6 and 7, respectively. Table 1 summarizes some of the

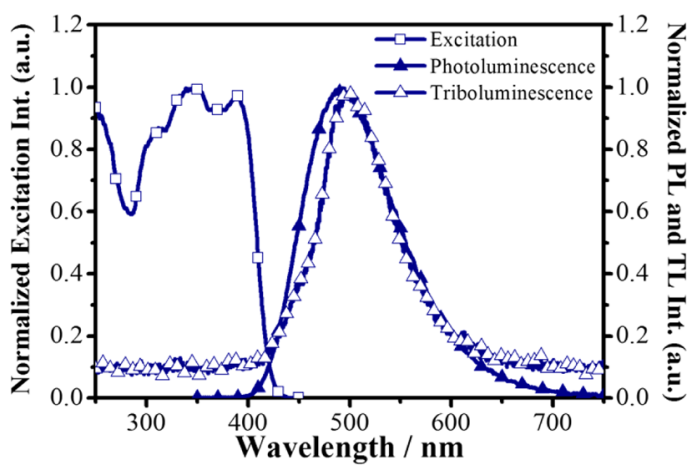

Figure 6. Excitation, PL, and TL emission spectra of the $\mathrm{Cu}(\mathrm{NCS})$ $(\mathrm{py})_{2}\left(\mathrm{PPh}_{3}\right)$ complex in the solid state.

data extracted from those curves. The complex presented higher optical band gaps $\left(E_{\text {opt }}\right)$ as a result of blue-shifted excitation spectra in all of the polymeric fiber mats. This shift was at a negligible level in the surface-impregnated films. However, in blended composites more than a $0.5 \mathrm{eV}$ blue shift is accompanied by a broadening of the PL emission spectra $\left(\lambda_{\text {ext }}\right.$ $=307 \mathrm{~nm}$ ), which reveals the possibility of H-type aggregate formation as result of face-to-face interactions of the complex in those polymeric fiber mats. ${ }^{45}$ This situation is further confirmed by the reduced absolute fluorescence quantum yield $\left(\Phi_{\mathrm{f}}\right)$ measured in those composites. The $\Phi_{\mathrm{f}}$ value of the solid complex is $98 \%$, and the highest $\Phi_{\mathrm{f}}$ value that is achieved with the blended polymer mats is $1.75 \%$ (in the PU matrix). Surfaceimpregnated polymer mats exhibited higher fluorescence quantum yields.

The TL emission spectrum of the bare complex was redshifted $10 \mathrm{~nm}$ and displayed a narrower distribution compared to the PL emission with a peak centered at $500 \mathrm{~nm}$ (Figure 6). The full width at half-maximum (fwhm) difference between the PL and TL emissions was more than $20 \mathrm{~nm}$ (Table 1). As stated above, no TL response could be detected from blended films, and no significant difference in the maximum TL emission wavelength is observed between the surfaceimpregnated composite mats. The main TL emission band of the composite occurs at 497, 496, 498, and $496 \mathrm{~nm}$ in the order of PMMA, PS, PU, and PVDF, whereas these values are 490, 490, 497, and $490 \mathrm{~nm}$, respectively, for the PL curves. Except for the PU matrix, a red shift in TL responses, compared to the PL maxima, is detected for all of the surface-impregnated polymer mats. The spectral differences between TL and PL emissions have been explained by self-absorption possibilities, pressure-induced changes in the Franck-Condon factors, the fracture-induced formation of different excited states, and the scattering of photons. ${ }^{46}$ In terms of excitation and PL emission spectra of the complex, independent from the matrix, the selfabsorption possibility plays a minor role when the integral of overlapped regions is taken into consideration. The red shift in TL emission spectra may arise from the pressure-induced changes, which is defined as altering the spectral feature due to the generation of different excited energy states by mechanical 

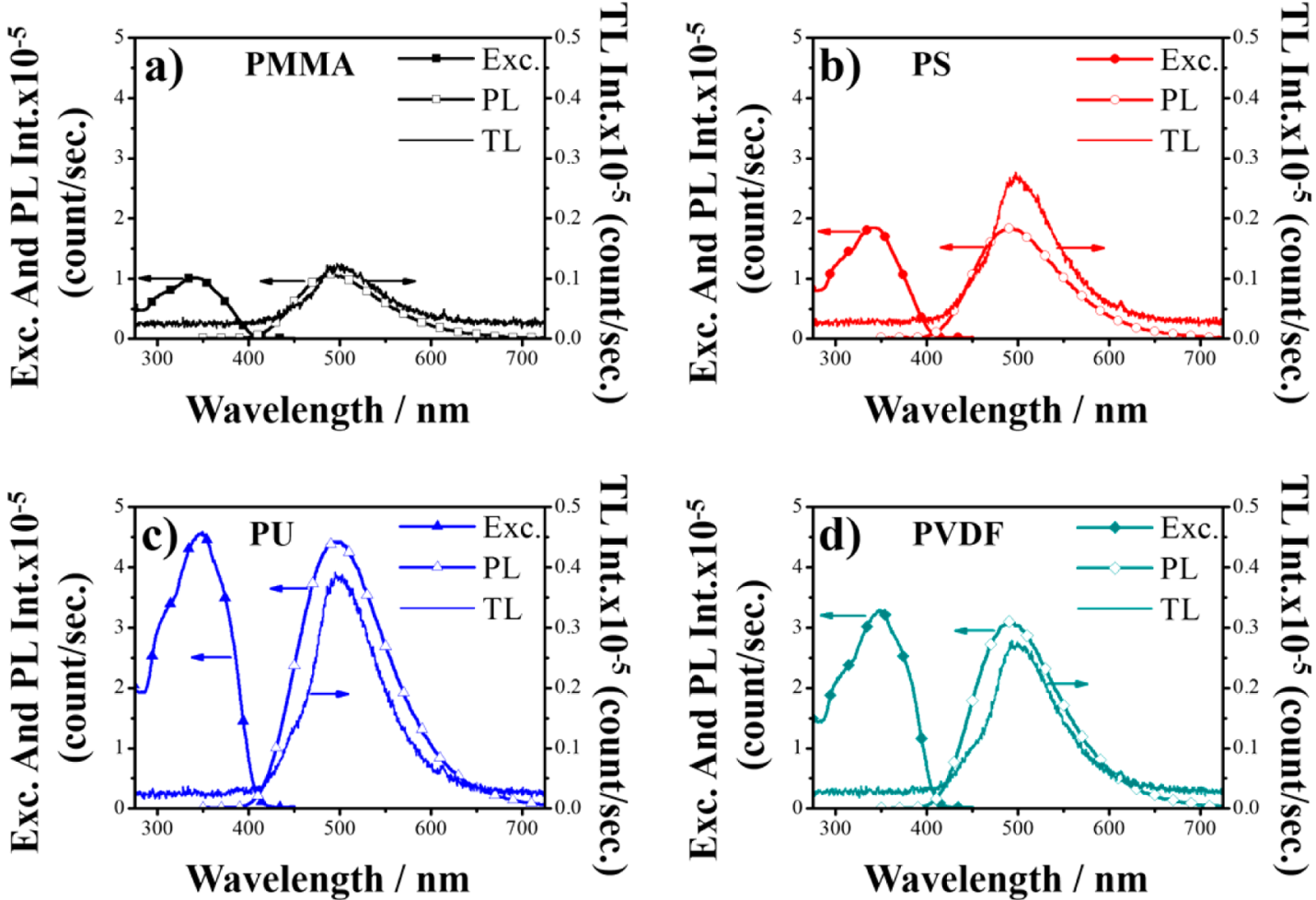

Figure 7. Excitation, PL, and TL emission spectra of the composite fiber mats [PMMA (a), PS (b), PU (c), and PVDF (d)] prepared by surface impregnation with respect to the chemistry of the polymer.

Table 1. Photophysical Data for the $\mathrm{Cu}(\mathrm{NCS})(\mathrm{py})_{2}\left(\mathrm{PPh}_{3}\right)$ Complex and Its Composite with Polymeric Mats ${ }^{a}$

\begin{tabular}{|c|c|c|c|c|c|c|c|}
\hline \multicolumn{2}{|c|}{$\mathrm{Cu}(\mathrm{NCS})(\mathrm{py})_{2}\left(\mathrm{PPh}_{3}\right)$} & $\lambda^{\text {PLmax }}{ }_{\text {emis }}(\mathrm{nm})$ & $\mathrm{fwhm}^{\mathrm{PL}}$ & $\lambda^{\mathrm{TLmax}}{ }_{\mathrm{emis}}(\mathrm{nm})$ & fwhm ${ }^{T L}$ & $E_{\text {opt }}(\mathrm{eV})^{b}$ & $\Phi_{\mathrm{f}}(\%)$ \\
\hline solid & bare & 490 & 113 & 500 & 90 & 2.92 & 98 \\
\hline surface-impregnated & PMMA & 490 & 113 & 497 & 87 & 3.06 & 30.8 \\
\hline & PS & 490 & 107 & 496 & 85 & 3.05 & 34.7 \\
\hline & PU & 497 & 116 & 498 & 86 & 3.05 & 87.7 \\
\hline & PVDF & 490 & 112 & 496 & 85 & 3.00 & 52.9 \\
\hline blended & PMMA & 512 & 130 & NA & NA & 3.44 & 0.285 \\
\hline & PS & 519 & 127 & NA & NA & 3.53 & 0.503 \\
\hline & PU & 525 & 140 & NA & NA & 3.57 & 1.75 \\
\hline & PVDF & 519 & 143 & NA & NA & 3.55 & 0.863 \\
\hline
\end{tabular}

${ }^{a} E_{\text {opt }}$ and PL data of blended composite mats are extracted from Figure S3. ${ }^{b}$ Calculated from the offset of the excitation spectra.

action. This explanation is further supported by the lifetime measurements that were all on the nanosecond scale (data not shown here), short enough to allow the effects of pressureinduced changes. ${ }^{46}$

The TL emission intensities and $\Phi_{\mathrm{f}}$ values of the polymer mats increase in the order of PMMA $<$ PS $<$ PVDF $<$ PU (inverse order of fiber diameters). Among the studied polymers, PU exhibited the highest $\Phi_{\mathrm{f}}$ values and the minimum spectral difference between the TL and PL emissions. This situation is attributed to the chemical composition of PU, which contains phenyl rings and carbonyl groups that may provide a medium for van der Waals, $\pi-\pi$, and dipole-dipole interactions between the complex and the polymer matrix. Additionally, these interactions may be motivated by the lower fiber diameter of PU polymer mats.

\section{CONCLUSIONS}

Organometallic-based triboluminescent complex $\mathrm{Cu}(\mathrm{NCS})$ (py $)_{2}\left(\mathrm{PPh}_{3}\right)$ was synthesized and utilized as a mechanosensing platform using electropsun fiber mats of four different polymer matrices: PMMA, PS, PU, and PVDF. The newly designed composite system by the surface impregnation of crystalline particles on the electrospun mats leads to potential applications in the development of smart optical probes. Notably, the PUbased composite also exhibits an impressive TL response with extended mechanical action due to an electrospun mat with the thinnest fiber network formation. Additionally, the photophysical properties of the composite, such as solid-state PL and TL, show compatible spectral characteristics. This result implies that the PU with chemical affinity wraps the $\mathrm{Cu}(\mathrm{I})$ complex and keeps the luminescence transitions at the same level. This system offers a high quantum yield, long-lived detectable TL response, and higher PL efficiency.

\section{ASSOCIATED CONTENT}

\section{Supporting Information}

The Supporting Information is available free of charge on the ACS Publications website at DOI: 10.1021/acs.jpcc.7b02875. 
TL response of a PU composite fiber prepared by blending, the fiber diameter of electrospun films, and the excitation and PL emission spectra of the composites prepared by blending (PDF)

\section{AUTHOR INFORMATION}

\section{Corresponding Author}

*E-mail: mdemir@iyte.edu.tr. Tel: +90 232750 7511. Fax: +90 2327507509.

\section{ORCID $\odot$}

Mustafa M. Demir: 0000-0003-1309-3990

\section{Present Address}

"Department of Biomedical Sciences, Biofilms Research Center for Biointerfaces, Faculty of Health and Society, Malmö University, SE 21432 Malmö, Sweden.

\section{Notes}

The authors declare no competing financial interest.

\section{ACKNOWLEDGMENTS}

We gratefully acknowledge the financial support provided by The Scientific and Technological Research Council of Turkey (TUBITAK) for the research encoded with KBAG-114Z292. We also thank the Center for Materials Research of the Izmir Institute of Technology for microscopy work and Prof. M. Emirdag-Eanes for fruitful discussions.

\section{REFERENCES}

(1) Leelachao, S.; Muraishi, S.; Sannomiya, T.; Shi, J.; Nakamura, Y. Correlation of triboluminescence and contact stresses in $\mathrm{ZnS}: \mathrm{Mn} /$ polymeric matrix composite. J. Lumin. 2016, 170, 24-29.

(2) Olawale, D. O.; Dickens, T.; Sullivan, W. G.; Okoli, O. I.; Sobanjo, J. O.; Wang, B. Progress in triboluminescence-based smart optical sensor system. J. Lumin. 2011, 131, 1407-1418.

(3) Fontenot, R. S.; Hollerman, W. A.; Bhat, K. N.; Aggarwal, M. D. Synthesis and characterization of highly triboluminescent doped europium tetrakis compounds. J. Lumin. 2012, 132, 1812-1818.

(4) Hurt, C. R.; McAvoy, N.; Bjorklund, S.; Filipescu, N. High Intensity triboluminescence in europium tetrakis (Dibenzoylmethide)triethylammonium. Nature 1966, 212, 179-180.

(5) Fontenot, R. S.; Owens, C. A.; Bhat, K. N.; Hollerman, W. A.; Aggarwal, M. D. Magnesium tetrakis dibenzoylmethide triethylammonium: A novel blue emitting phosphor. Mater. Lett. 2015, 146, 9-11.

(6) Jin, X.; Götz, M.; Wille, S.; Mishra, Y. K.; Adelung, R.; Zollfrank, C. A. novel concept for self-reporting materials: Stress sensitive photoluminescence in zno tetrapod filled elastomers. Adv. Mater. 2013, 25, 1342-1347.

(7) Chandra, B. P.; Sonwane, V. D.; Haldar, B. K.; Pandey, S. Mechanoluminescence glow curves of rare-earth doped strontium aluminate phosphors. Opt. Mater. 2011, 33, 444-451.

(8) Xu, C. N.; Yamada, H.; Wang, X. S.; Zheng, X. G. Strong elasticoluminescence from monoclinic-structure $\mathrm{SrAl}_{2} \mathrm{O}_{4}$. Appl. Phys. Lett. 2004, 84, 3040-3042.

(9) Sohn, K. S.; Seo, S. Y.; Kwon, Y. N.; Park, H. D. Direct observation of crack tip stress field using the mechanoluminescence of $\mathrm{SrAl}_{2} \mathrm{O}_{4}$ :(Eu,Dy,Nd). J. Am. Ceram. Soc. 2002, 85, 712-714.

(10) Ishihara, T.; Tanaka, K.; Fujita, K.; Hirao, K.; Soga, N. Full color triboluminescence of rare-earth-doped hexacelsian $\left(\mathrm{BaAl}_{2} \mathrm{Si}_{2} \mathrm{O}_{8}\right)$. Solid State Commun. 1998, 107, 763-767.

(11) Wu, W.; Narisawa, T.; Hayashi, S. Triboluminescence of 3,6dibromocarbazole. Jpn. J. Appl. Phys. 2001, 40, 1294-1296.

(12) Nowak, R.; Krajewska, A.; Samoc, M. Efficient Triboluminescence in N-isopropylcarbozale. Chem. Phys. Lett. 1983, 94, 270-271.

(13) Sweeting, L. M.; Rheingold, A. L.; Gingerich, J. M.; Rutter, A. W.; Spence, R. A.; Cox, C. D.; Kim, T. J. Crystal structure and triboluminescence 0.2 . 9-anthracenecarboxylic acid and its esters. Chem. Mater. 1997, 9, 1103-1115.

(14) Nakayama, H.; Nishida, J.; Takada, N.; Sato, H.; Yamashita, Y. Crystal structures and triboluminescence based on trifluoromethyl and pentafluorosulfanyl substituted asymmetric N-Phenyl imide compounds. Chem. Mater. 2012, 24, 671-676.

(15) Marchetti, F.; Di Nicola, C.; Pettinari, R.; Timokhin, I.; Pettinari, C. Synthesis of a photoluminescent and triboluminescent copper(i) compound: An experiment for an advanced inorganic chemistry laboratory. J. Chem. Educ. 2012, 89, 652-655.

(16) İncel, A.; Reddy, S. M.; Demir, M. M. A new method to extend the stress response of triboluminescent crystals by using hydrogels. Mater. Lett. 2017, 186, 210-213.

(17) Encinas, J. C.; Castillo-Ortega, M. M.; del Castillo-Castro, T.; Castano, V. M. Triboluminescence of poly(n-butyl methacrylate)polyaniline composites. Mater. Res. Innovations 2006, 10, 262-267.

(18) Meuer, S.; Zentel, R. Functional diblock copolymers for the integration of triboluminescent materials into polymer matrices. Macromol. Chem. Phys. 2008, 209, 158-167.

(19) Eliseeva, S. V.; Pleshkov, D. N.; Lyssenko, K. A.; Lepnev, L. S.; Bunzli, J. C. G.; Kuzminat, N. P. Highly luminescent and triboluminescent coordination polymers assembled from lanthanide beta-diketonates and aromatic bidentate o-donor ligands. Inorg. Chem. 2010, 49, 9300-9311.

(20) Olawale, D. O.; Sullivan, W.; Dickens, T.; Okoli, O.; Wang, B. Mimicking the human nervous system with a triboluminescence sensory receptor for the structural health monitoring of composite structures. Proc. SPIE 2011, 7981, 798125.

(21) Hasegawa, Y.; Hieda, R.; Miyata, K.; Nakagawa, T.; Kawai, T. Brilliant triboluminescence of a lanthanide coordination polymer with low-vibrational-frequency and non-centrosymmetric structural networks. Eur. J. Inorg. Chem. 2011, 2011, 4978-4984.

(22) Dickens, T. J.; Breaux, J.; Olawale, D. O.; Sullivan, W. G.; Okoli, O. I. Effects of $\mathrm{ZnS}: \mathrm{Mn}$ concentrated vinyl ester matrices under flexural loading on the triboluminescent yield. J. Lumin. 2012, 132, 1714-1719.

(23) Vettegren, V. I.; Lyashkov, A. I.; Savitskii, A. V.; Shcherbakov, I. P.; Vasil'ev, K. D. Microcrack dynamics in a polymer composite material during friction. Tech. Phys. 2012, 57, 1445-1448.

(24) Hiratsuka, K.; Hosotani, K. Effects of friction type and humidity on triboelectrification and triboluminescence among eight kinds of polymers. Tribol. Int. 2012, 55, 87-99.

(25) Fontenot, R. S.; Hollerman, W. A.; Bhat, K. N.; Aggarwal, M. D.; Penn, B. G. Incorporating strongly triboluminescent europium dibenzoylmethide triethylammonium into simple polymers. Polym. J. 2014, 46, 111-116.

(26) Onodera, H.; Kitagawa, Y.; Nakanishi, T.; Fushimi, K.; Hasegawa, Y. Acid-protected $\mathrm{Eu}(\mathrm{III})$ coordination nanoparticles covered with polystyrene. J. Mater. Chem. C 2016, 4, 75-81.

(27) Olawale, D. O.; Yan, J.; Bhakta, D. H.; Carey, D.; Dickens, T. J.; Okoli, O. I. In In pursuit of bio-inspired triboluminescent multifunctional composites. In Mechanics of Composite and Multifunctional Materials; Ralph, C.; Silberstein, M.; Thakre, P. R.; Singh, R., Eds.; Springer: Cham, Germany, 2016; Vol 7, pp 55-65.

(28) Fontenot, R. S.; Allison, S. W.; Lynch, K. J.; Hollerman, W. A.; Sabri, F. Mechanical, spectral, and luminescence properties of $\mathrm{ZnS}: \mathrm{Mn}$ doped PDMS. J. Lumin. 2016, 170, 194-199.

(29) George, T. M.; Sajan, M. J.; Gopakumar, N.; Reddy, M. L. P. Bright red luminescence and triboluminescence from PMMA-doped polymer film materials supported by $\mathrm{Eu}^{3+}$-triphenylphosphine based beta-diketonate and 4,5-bis(diphenylphosphino)-9,9-dimethylxanthene oxide. J. Photochem. Photobiol., A 2016, 317, 88-99.

(30) Balazs, A. C.; Emrick, T.; Russell, T. P. Nanoparticle polymer composites: Where two small worlds meet. Science 2006, 314, 11071110.

(31) Behler, K. D.; Stravato, A.; Mochalin, V.; Korneva, G.; Yushin, G.; Gogotsi, Y. Nanodiamond-polymer composite fibers and coatings. ACS Nano 2009, 3, 363-369. 
(32) Breuer, O.; Sundararaj, U. Big returns from small fibers: A review of polymer/carbon nanotube composites. Polym. Compos. 2004, 25, 630-645.

(33) Bruns, N.; Pustelny, K.; Bergeron, L. M.; Whitehead, T. A.; Clark, D. S. Mechanical nanosensor based on FRET within a thermosome: Damage-reporting polymeric materials. Angew. Chem., Int. Ed. 2009, 48, 5666-5669.

(34) Choi, C. L.; Koski, K. J.; Sivasankar, S.; Alivisatos, A. P. StrainDependent photoluminescence behavior of $\mathrm{CdSe} / \mathrm{CdS}$ nanocrystals with spherical, linear, and branched topologies. Nano Lett. 2009, 9, 3544-3549.

(35) Ciprari, D.; Jacob, K.; Tannenbaum, R. Characterization of polymer nanocomposite interphase and its impact on mechanical properties. Macromolecules 2006, 39, 6565-6573.

(36) Berber, E.; Horzum, N.; Hazer, B.; Demir, M. M. Solution electrospinning of polypropylene-based fibers and their application in catalysis. Fibers Polym. 2016, 17, 760-768.

(37) Demir, M. M.; Gulgun, M. A.; Menceloglu, Y. Z.; Erman, B.; Abramchuk, S. S.; Makhaeva, E. E.; Khokhlov, A. R.; Matveeva, V. G.; Sulman, M. G. Palladium nanoparticles by electrospinning from poly(acrylonitrile-co-acrylic acid)- $\mathrm{PdCl}_{2}$ solutions. Relations between preparation conditions, particle size, and catalytic activity. Macromolecules 2004, 37, 1787-1792.

(38) Demir, M. M.; Ugur, G.; Gulgun, M. A.; Menceloglu, Y. Z. Glycidyl-methacrylate-based electrospun mats and catalytic silver nanoparticles. Macromol. Chem. Phys. 2008, 209, 508-515.

(39) Horzum, N.; Tascioglu, D.; Ozbek, C.; Okur, S.; Demir, M. M. VOC sensors based on a metal oxide nanofibrous membrane/QCM system prepared by electrospinning. New J. Chem. 2014, 38, 57615768.

(40) Demir, M. M.; Horzum, N.; Oezen, B.; Oezcelik, S. Hierarchial coassembly of a cyanine dye in poly(vinyl alcohol) fibrous films by electrospinning. J. Phys. Chem. B 2013, 117, 10920-10928.

(41) Demir, M. M.; Yilgor, I.; Yilgor, E.; Erman, B. Electrospinning of polyurethane fibers. Polymer 2002, 43, 3303-3309.

(42) Sheldrick, G. M. A short history of SHELX. Acta Crystallogr., Sect. A: Found. Crystallogr. 2008, 64, 112-122.

(43) İncel, A.; Emirdag-Eanes, M.; McMillen, C. D.; Demir, M. M. Integration of triboluminescent EuD4TEA crystals to transparent polymers: Impact sensor application. ACS Appl. Mater. Interfaces 2017, 9, 6488-6496.

(44) Fontenot, R. S.; Bhat, K. N.; Hollerman, W. A.; Aggarwal, M. D.; Nguyen, K. M. Comparison of the triboluminescent yield and decay time for europium dibenzoylmethide triethylammonium synthesized using different solvents. CrystEngComm 2012, 14, 1382-1386.

(45) Demir, M. M.; Ozen, B.; Ozcelik, S. Formation of pseudoisocyanine J-Aggregates in poly(vinyl alcohol) fibers by electrospinning. J. Phys. Chem. B 2009, 113, 11568-11573.

(46) Duignan, J. P.; Oswald, I. D. H.; Sage, I. C.; Sweeting, L. M.; Tanaka, K.; Ishihara, T.; Hirao, K.; Bourhill, G. Do triboluminescence spectra really show a spectral shift relative to photoluminescence spectra? J. Lumin. 2002, 97, 115-126. 